\title{
Situações de vida, pobreza e saúde: estratégias alimentares e práticas sociais no meio urbano
}

\author{
Living situations, poverty and health: \\ alimentary strategies and social practices \\ in the urban environment
}

\footnotetext{
${ }^{1}$ Departamento de Assistência e Orientação Profissional. Universidade Federal do Rio Grande do Sul, Escola de Enfermagem. Rua São Manuel 963, 90620-110, Porto Alegre RS. tatiana.gerhardt@ufrgs.br
}

\begin{abstract}
This study introduces the importance of the practices and strategies of the lower classes population in facing their daily problems in order to direct actions to Collective Health. Unveiling the ways of struggle of these classes, concerning their health-disease process, implies to identify the practices connected direct or indirectly with health, and in this specific study, with feeding. The study indicates a methodology (interdisciplinary) and the concepts related to practices, strategies, living situations and health. The different social categories create strategies based on their logic of action and on their experiences and life stories. The study sets out that the comprehension of the ways of facing their daily problems includes the use of strategies that (re)appropriate and (re)construct their knowledge, and it also points out that the identification of the existing social network facilitates the acknowledgment of these practices and the direction of the Collective Health actions.
\end{abstract}

Key words Strategies, Inter-aid networks, Feeding, Interdisciplinarity, Living situations
Resumo Este estudo trata da importância das práticas e estratégias da população de baixa renda no enfrentamento dos problemas cotidianos. Visa ao direcionamento de ações em saúde coletiva. Desvendar as formas de enfrentamento desses grupos populacionais tem a ver com o processo saúde-doença, e neste estudo específico, com a alimentação. O estudo indica uma opção metodológica interdisciplinar e conceitual, relacionando conceitos de práticas, estratégias, situações de vida e saúde. Parte-se do princípio de que a compreensão das formas de enfrentamento da realidade pela população de baixa renda abrange a utilização de estratégias num processo de (re)apropriação e (re) construção de saberes e de que a identificação das redes sociais facilitam o reconhecimento dessas práticas e o direcionamento das ações em saúde coletiva.

Palavras-chave Estratégias, Redes de entreajuda, Alimentação, Interdisciplinaridade, Situações de vida 


\section{Introdução}

A alimentação ocupa uma posição importante na sociedade da cidade de Paranaguá e é uma prioridade na vida cotidiana das famílias, fato que não é novo, pois o acesso à alimentação constitui um problema que toda a sociedade deve enfrentar e encontrar soluções para poder se reproduzir fisicamente. Isso é ainda mais visível para as famílias mais carentes que necessitam elaborar estratégias para minimizar o impacto das restrições econômicas e poder assim enfrentar a escassez alimentar. Se de uma maneira geral, a composição dos pratos consumidos e a estrutura das refeições não variam muito entre as famílias das diversas categorias sociais, os diferentes modos de avaliar os problemas conduzem as famílias a adotarem estratégias distintas que respondem melhor as suas necessidades específicas.

As modalidades técnicas, sociais e econômicas da alimentação revelam assim algumas opções sociais, expressam certas estratégias econômicas, colocam em prática técnicas de preparação e de relações sociais específicas. Expressam também as condições a que são submetidas às famílias e o grau de flexibilidade que elas dispõem para se adaptarem às restrições econômicas, atuando de forma diferenciada sobre o processo saúde-doença.

Para examinar a forma como as situações de vida, a pobreza e a saúde se traduzem de forma concreta na vida cotidiana, e particularmente na alimentação dos citadinos, procurei em Paranaguá a ilustração concreta do ambiente de vida urbano. O presente estudo se desenvolveu no âmbito do programa de pesquisa interdisciplinar intitulado "Espaço urbano, situações de vida e saúde: o caso de Paranaguá”, do curso de doutorado em meio ambiente e desenvolvimento da Universidade Federal do Paraná/Université de Bordeaux 2, cuja temática abordou as relações entre desigualdades sociais e de saúde. A situação observada em Paranaguá não é comparável a das grandes metrópoles brasileiras, nem mesmo à Curitiba, capital do Estado do Paraná, mas trata-se de uma cidade com uma densidade humana elevada, um rápido crescimento demográfico ( $4 \%$ ao ano desde 1940) e com problemas importantes de urbanismo e de emprego. Seu tamanho, ainda de porte médio (em torno de 115.000 habitantes em 1997), constitui uma vantagem no plano científico, pois possibilita a aplicação de uma abordagem que permite ter uma visão do seu conjunto de forma aprofundada e o desenvolvimento de um programa de pesquisa interdisciplinar.

A cidade de Paranaguá apresentou nos últimos 40 anos um quadro urbano de crescimento populacional acelerado em que as dinâmicas de ocupação territorial urbana não foram acompanhadas da correspondente expansão da infra-estrutura de redes de abastecimento de água, rede de esgotos, coleta de lixo, pavimentação e energia elétrica, e ampliação da cobertura de serviços essenciais, como educação, saúde e outros. O rápido crescimento urbano de Paranaguá, decorrente de migrações ruralurbano e urbano-urbano e de taxas de crescimento vegetativo ainda elevadas, acarretou não só transformações no meio físico, mas também transformações sociais. Esse processo de transformações na sociedade urbana não se fez de modo homogêneo no espaço urbano, mas ocorreu de diversos modos, criando uma diversificação que compõe um quadro de heterogeneidades espaciais e desigualdades sociais.

O estado de saúde da população de Paranaguá, avaliado no seu conjunto pelos dados de mortalidade e morbidade, revela uma situação mais precária que o Estado do Paraná e muito mais que a cidade de Curitiba. A primeira situação é a da mudança gradativa do perfil de mortalidade em que começam a aparecer mais nitidamente os problemas do envelhecimento populacional, porém ainda persistem problemas revelados pelas altas taxas de mortalidade infantil e materna. Outra situação é a persistência de problemas infecciosos e parasitários que não condiz com uma melhoria da situação de saúde devido a melhorias de condições de vida generalizadas, mas faz supor que essas melhorias sejam vivenciadas apenas por alguns grupos da população.

$\mathrm{Na}$ assistência à saúde, embora pareça ter ocorrido um aumento do acesso da população aos serviços básicos, questões importantes, como a assistência adequada à gestação e ao parto, ainda não parecem ser extensivas a toda a população. Todas essas observações retomam o problema das disparidades em saúde não só no sentido de constatá-las, mas de como enfrentálas e superá-las num contexto de grandes heterogeneidades espaciais e desigualdades sociais.

Por sua vez essa problemática pensada teoricamente é inserida no contexto local particular, que foi objeto de um programa de pesquisa interdisciplinar do qual faz parte este estudo. As informações sobre a situação da cidade co- 
mo um todo e as particularidades intra-urbanas, obtidas ao longo das pesquisas interdisciplinar e disciplinar, são o pano de fundo dos meus questionamentos sobre as práticas e estratégias alimentares desenvolvidas pelas famílias com condições de vida precárias que constituíram o centro do meu objeto de pesquisa (Gerhardt, 2000).

A problemática antropológica foi centrada assim na capacidade dos indivíduos em mobilizar recursos ou formular estratégias de enfrentamento de seus problemas cotidianos e de suas necessidades básicas: hipóteses que guiaram esta investigação. Essa capacidade é modelada por histórias de vida, pela experiência vivida pelos indivíduos e suas famílias, pela dinâmica individual que resulta disto ou até mesmo pela personalidade individual. Cada um interpreta e constrói sua situação de vida, que varia nas diferentes zonas da cidade e nos diferentes estratos socioeconômicos.

A vida na cidade, de forma geral, apresenta hoje uma disparidade crescente que divide as diferentes categorias sociais, sobretudo em termos de emprego, renda, moradia, meio físico, alimentação e saúde. A saúde e a alimentação constituem um elemento central e essencial para a reprodução dos grupos humanos; representam um campo propício à avaliação objetiva do quadro de vida urbano, nos seus componentes materiais e sociais, e do que ele pode ocasionar sobre o corpo físico dos indivíduos; e, no campo antropológico, portanto, trata-se de mais um ângulo de análise da sociedade, um campo revelador do seu funcionamento. As estratégias desenvolvidas pelos indivíduos e os discursos que as acompanham são elaborados a partir de instituições, representações coletivas e relações sociais preexistentes, que os indivíduos reinterpretam, recompõem, em função das situações e restrições que se apresentam. A abordagem das dinâmicas sociais requer o entendimento da articulação entre o social e o cultural. Exige também que seja explorada a relação dialética que sempre se estabelece, na construção das realidades sociais, entre as determinações de caráter estrutural e coletivo e o papel inovador das atuações individuais - o que representa outro desafio científico (Gerhardt, 2002).

Distanciamo-nos então da visão segundo a qual as práticas e as representações individuais seriam totalmente impostas pelo contexto material, social e cultural de sua existência para levar em conta as dinâmicas, os conflitos e as contradições. No campo antropológico, o objeto da alimentação e saúde é pertinente e susceptível de contribuir para abordar as relações entre o individual e o social. $\mathrm{O}$ desafio consiste em conciliar a atenção legítima dada ao ator individual com a preocupação de identificar o que, no seu universo cultural (complexo, diversificado e em transformação), forma e informa as suas decisões e suas escolhas. Esse campo é particularmente fecundo para a abordagem da esfera pública e particular, do individual e coletivo, na medida em que saúde, doença e alimentação refletem-se no corpo dos indivíduos. Além disso, são um excelente revelador da complexidade e das dinâmicas e um caminho para ler a realidade urbana, o que já foi demonstrado em vários trabalhos desenvolvidos na África por Raynaut (1992a; b).

A partir dessas considerações - em termos de situações de vida -, foram abordadas as questões da alimentação. Essa noção, central a este estudo antropológico, mas também ao programa de pesquisa interdisciplinar como um todo, mostrou-se interessante, pois associa a utilização que os atores sociais fazem de suas condições materiais e imateriais, em função das percepções que eles constroem dos problemas e dificuldades materiais e imateriais aos quais estão submetidos, recompondo e reinterpretando os problemas. Além disso, essa noção tem o mérito de permitir um diálogo entre o que, na existência de um indivíduo - ou de um grupo -, provém de fatores contextuais problemáticos, sejam eles materiais, sociais ou culturais, e as interpretações e combinações que o indivíduo faz em função de suas próprias percepções, de seus objetivos e de sua capacidade em formular um projeto de vida. Nesse contexto dinâmico justamente é realizada a hierarquia dos problemas. A noção de situações de vida assim definida permite conciliar a existência de fatores objetivos de vulnerabilidade (condições materiais e sociais de vida) e a ação do sujeito como intérprete do real, e se torna um instrumento interessante para a compreensão da vulnerabilidade. Dessa maneira foram pensadas e analisadas as estratégias alimentares e as práticas sociais na cidade de Paranaguá.

\section{Materiais e métodos}

Num esforço de compreensão da dimensão humana do fenômeno de urbanização, a conseqüência metodológica destas asserções é a exis- 
tência de uma complementaridade entre as análises das várias formas de heterogeneidades: espaciais, socioeconômicas e sanitárias. Esse foi o alicerce teórico da interdisciplinaridade, aplicado ao estudo da cidade de Paranaguá, apresentado em Caneparo et al. (1996), Nazareno (1999) e Gerhardt (2000). O grande desafio metodológico para o estudo antropológico foi o de trabalhar com vários níveis de análise, em escalas sucessivas de aproximação da realidade, através de instrumentos e categorias de análise que permitiram ir além da visão global da cidade.

O primeiro nível de análise compreendeu um zoneamento através da análise cartográfica da cidade como instrumento para caracterizar as heterogeneidades espaciais (Caneparo et al., 1996; Gerhardt et al., 1996). No segundo nível de análise, foi elaborada uma estratificação social da população (obtida através do método estatístico de análise multivariada), instrumento que permitiu a descrição das disparidades internas de cada zona (Gerhardt et al., 1997). Após a elaboração da estratificação social, operou-se o confronto entre as duas categorias de análise: o espaço e a estratificação socioeconômica (Gerhardt et al. 1997).

Os resultados das enquetes precedentes (que se situam em um nível macro-social da realidade estudada) permitiram organizar um certo número de informações relativas ao contexto geral no qual se desenvolve a vida cotidiana. De fato, os resultados do zoneamento e da estratificação social (Gerhardt et al., 1996; 1997) mostram a existência de uma grande diversidade e complexidade no espaço urbano e na sociedade paranaguaense, em matéria de ambiente físico, moradia, demografia e vida social. Ao mesmo tempo, a cidade de Paranaguá apresenta diferenças importantes de níveis de vida. A situação sanitária abordada também em matéria de disparidades espaciais e de desigualdades sociais (pela enquete epidemiológica e em economia da saúde) mostra que, para certos indicadores, o estado de saúde dos indivíduos, a utilização das estruturas de cuidado e as diferenças estão ligadas aos aspectos socioeconômicos e as condições de vida materiais. Porém, indicadores ligados ao estado de saúde das crianças, sobretudo em relação à situação nutricional, mostram uma baixa relação com as disparidades espaciais e sociais, o que incita a reflexão sobre os limites da abordagem centrada nas condições de vida materiais das zonas e dos estratos socioeconômicos.
Não obstante, este nível de análise macrosocial traz uma contribuição importante no sentido de permitir construir um quadro geral que situa as diferentes situações e retoma algumas questões que puderam constituir a problemática antropológica em função de seus próprios conceitos. Para compreender a relação entre o estado de saúde, a pobreza e a alimentação, algumas vezes nítida e em outros casos pouco expressiva, foi necessário aprofundar a análise para um nível em que se desenvolvem estratégias de acordo com as lógicas utilizadas pelas populações; foi necessário também utilizar métodos de análise mais adequados à abordagem dos problemas que se colocam em nível das famílias e das respostas que são dadas pelos indivíduos aos problemas, de acordo com o conjunto de elementos da realidade (de ordem material, mas também cultural). Foi necessário, portanto, mudar de escala de análise e de olhar, passar da geografia, socioeconomia, epidemiologia à antropologia.

Algumas questões levantadas no nível mais global foram retomadas pela antropologia: as zonas da cidade não são homogêneas, dentro delas "co-residem" diferentes categorias sociais que, mesmo se situando em um contexto espacial igual, dispõem de meios distintos para encontrar respostas aos problemas que se apresentam. A alimentação e a saúde dos indivíduos expressam o impacto sobre o corpo dos problemas materiais, e permitem, de um certo modo, uma leitura dessas relações. Por outro lado, existem mecanismos de regulação ou de perturbação da alimentação e da saúde que são de ordem social e cultural, a saber:

a) Relações sociais (familiares e comunitárias) - solidariedades que as fortalecem ou conflitos que as dividem - como mediadores entre o indivíduo e seu ambiente físico. Os comportamentos e opiniões de indivíduos dependem em grande parte das estruturas nas quais estão inseridos e do sistema de valores e normas veiculados pelo meio social no interior do qual os indivíduos estão inseridos e ao qual fazem referência e que governam as relações entre ambiente - saúde - sociedade.

b) Conseqüências dos comportamentos individuais em relação às desordens corporais (físicas), de acordo com as representações do corpo e da doença e as respostas propostas pelos sistemas "tradicional" e "oficial" de cuidados em saúde.

A partir do momento em que não nos contentamos em saber que o estado de saúde de 
uma população é reflexo "passivo" das condições de vida materiais torna-se indispensável considerar as respostas sociais dadas aos problemas que se apresentam, sob a forma de gestão social, não exclusivamente da saúde e da doença, mas também da vida cotidiana como um todo, o que implica um esforço de compreensão dos problemas ligados à alimentação e a capacidade de mobilização de "recursos sociais", capazes de dar um tipo de resposta aos problemas encontrados e das trajetórias sociais que levam os indivíduos a se encontrarem em tal situação.

A pesquisa antropológica aprofundada realizou uma análise das respostas sociais dadas pelos indivíduos aos problemas cotidianos, e em especial em relação à alimentação, centrada nas famílias pertencentes às camadas de baixa renda, mas com capacidades diferentes de mobilização de recursos sociais e residentes em duas zonas privilegiadas pela pesquisa: Ilha de Valadares e Franjas. A investigação antropológica foi conduzida por uma amostra estabelecida de acordo com um certo número de critérios: foram selecionadas famílias de acordo com a posição na hierarquia social, com o potencial de mobilização de recursos sociais e com a localização nas diferentes zonas da cidade (Gerhardt, 2000).

A metodologia seguida nesta pesquisa visou responder a um desafio, o de saber articular as exigências do método antropológico com as questões levantadas pela saúde pública em um programa de pesquisa interdisciplinar.

\section{Resultados}

Ter moradia, alimentação, condições de higiene e acesso aos serviços de saúde é hoje um importante problema para uma boa parte da população da cidade de Paranaguá, sobretudo para aquela que reside nos bairros periféricos e que pertence às camadas desfavorecidas da população. O fato não é novo na sociedade brasileira como um todo. No contexto específico de Paranaguá - em transformação e crescimento intenso e onde quase metade da população é migrante -, o acesso às condições de vida de base é fruto de estratégias complexas que levam em conta os problemas materiais e econômicos, tentando conciliá-los com os objetivos de ordem social. De acordo com a sua trajetória migrantes ou não-migrantes - e sua situação econômica, os indivíduos procuram soluções diferentes. Alguns tomam em mãos suas con- dições de existência, outros, ao contrário, são confrontados a uma depressão física e moral. Ser pobre na cidade significa antes de tudo a procura de um caminho que permita a sobrevivência a estas populações. Os múltiplos itinerários que conduzem a sobrevivência originam assim uma grande diversidade de situações de vida.

As informações reunidas no quadro da pesquisa interdisciplinar forneceram uma visão global do ambiente material, econômico, social e cultural da sociedade em questão e de ver como o "social" modula, em cada nível de análise (espacial, socioeconômico, familiar), a vida cotidiana e o estado de saúde individual. Elas também permitiram compreender as diferentes estratégias colocadas em prática pelas famílias de baixa renda a fim de assegurar a sobrevivência.

Certos aspectos merecem ser retomados aqui, aqueles que, por uma aproximação global, fizeram intervir uma pluralidade de fatores e nos conduziram, por um lado, a demonstrar a existência de fortes desigualdades sociais na sociedade paranaguaense, e, por outro lado, a analisar o modo pelo qual as famílias de baixa renda enfrentam suas condições econômicas e as restrições alimentares.

As desigualdades sociais são em primeiro lugar o fruto de um contexto mais amplo (histórico, social, econômico e político), que se refere ao processo de formação e crescimento de Paranaguá: cidade portuária que conheceu a partir dos anos 50 um período de crescimento econômico e demográfico intenso e rápido. Mais recentemente, o que se observa é uma redução do papel do porto na oferta de atividades e de recursos que alimentam o desenvolvimento urbano (redução da mão de obra e das atividades econômicas). O fenômeno é resultado da modernização das atividades portuárias. Não obstante, a população da cidade continua a crescer $(30 \%$ do crescimento da população provêm do saldo migratório), o que confirma a qualidade de pólo de atração, e isso até mesmo em um período recente. Ainda, a análise das características e dinâmicas do espaço e da sociedade urbana de Paranaguá mostrou os grandes eixos de diferenciação presentes atualmente na cidade: zonas muito distintas e grandes disparidades entre as categorias socioeconômicas. O resultado do zoneamento espacial compreende cinco grandes zonas e constitui a base de descrição das heterogeneidades espaciais da cidade, instrumento comum a todos os pesquisadores da equipe, cujas características descriti- 
vas se resumem sinteticamente da melhor zona em termos de infra-estrutura, serviços, condições de vida, etc. que se situam no centro urbano, até as piores zonas, segundo esses critérios, como as Franjas e a Ilha de Valadares (Figura 1). A estratificação social por sua vez comportou um modelo final de três estratos socioeconômicos: superior (222 famílias, 35\% da população total), médio (240 famílias, 38\% da população total), inferior (177 famílias, $28 \%$ da população total).

O confronto entre esses dois instrumentos de análise é demonstrado na figura 2, na qual se observa que se os níveis econômicos estão presentes em todas as zonas da cidade, existe uma forte relação entre o recorte espacial e a distribuição da população em função dos estratos. $\mathrm{O}$ estrato superior está presente em todas as zonas e sua proporção diminui progressivamente do centro urbano em direção a Ilha de Valadares. O estrato inferior apresenta um perfil inverso ao do estrato superior, aumentando progressivamente sua proporção no centro urbano, em direção as Franjas e Ilha de Valadares.

A combinação das duas dimensões (espacial e social) constitui um quadro geral de análise com o qual a antropologia não pode se contentar para avaliar a pobreza e as desigualdades sociais, pois não permite desvendar as condições e dificuldades individuais ou familiares cotidianas no acesso aos bens e serviços, na medida em que múltiplos fatores determinantes intervêm na vida cotidiana. Daí a necessidade de aprofundar a análise, sobretudo no que diz respeito à resolução de problemas alimentares cotidianos.

Assim, Ilha de Valadares e Franjas foram duas zonas escolhidas para o desenvolvimento da pesquisa antropológica aprofundada, por se distinguirem claramente no plano do ambiente físico, sanitário, social e cultural. A primeira zona, de ocupação mais antiga e cuja população é originária de pequenas comunidades de agricultores e pescadores da região, está ainda ligada à "cultura rural", ao mesmo tempo em que se beneficia do quadro de vida urbano. Nesse sentido, o parentesco geograficamente próximo fornece às famílias um quadro econômico e social que lhes permite resistir, até certo ponto, à precariedade material. Ele constitui o elemento mais estável da estrutura social. A segunda zona, as Franjas, de ocupação recente e cuja população é, na sua maioria, originária da própria cidade de Paranaguá, partilha muito mais a cultura urbana e encontra-se em uma situação de maior ruptura com o parentesco.

Sendo assim, ser pobre na Ilha de Valadares, onde a rede de parentesco é mais próxima e os laços sociais são intensos, conduz à formulação de estratégias de sobrevivência diferentes dos pobres que moram nas Franjas. O parentesco possui um papel importante entre as famílias carentes na sobrevivência dos moradores de Valadares, o que já não acontece com os moradores das Franjas que buscam no seio do núcleo familiar (no sentido de família nuclear) e da comunidade o desenvolvimento de estratégias de sobrevivência para o presente; buscam construir o futuro e pensar o passado. A valorização da família e do parentesco entre os mais desfavorecidos é o resultado da forma como eles vivem suas próprias condições de vida, seus projetos, e de como eles se posicionam diante das outras categorias sociais. A vida familiar e comunitária não está, então, isolada; ela se insere na dinâmica econômica e social da sociedade como um todo e na capacidade individual de integrar-se a ela.

A precariedade do mercado de trabalho e a instabilidade do trabalho portuário são dificuldades importantes que uma boa parte da população de Paranaguá deve enfrentar. A informalidade confere aos chefes de família um estatuto que lhes oferece menos possibilidades de acumulação, mas trata-se de uma categoria interessante para a análise das situações de vida, pois faz intervir diferentes estratégias colocadas em prática pelos atores sociais. As zonas das Franjas e da Ilha de Valadares concentram o maior número de chefes de família que não possuem trabalho formal, mas que tentam de alguma forma ganhar sua vida no dia-a-dia. Existe uma diversidade de situações em termos de procura de trabalho informal. A procura cotidiana de trabalho não é algo simples e fácil, e dentre os chefes que procuram um trabalho informal, alguns conseguem e outros não. Para estes últimos, outras estratégias são colocadas em prática, particularmente apoiando-se em redes de troca e de entre-ajuda ou apelando a instituições de ajuda social (prefeitura, igrejas), que podem contribuir ao estabelecimento de relações de dependência em relação às instituições. De certa forma, além da ajuda material que prestam, esses serviços funcionam como agentes de integração, de socialização e de solidariedade para as populações mais carentes. Em um país onde a presença do Estado é cada vez menor, as religiões ocupam esse espaço 
Figura 1

Zoneamento da cidade de Paranaguá

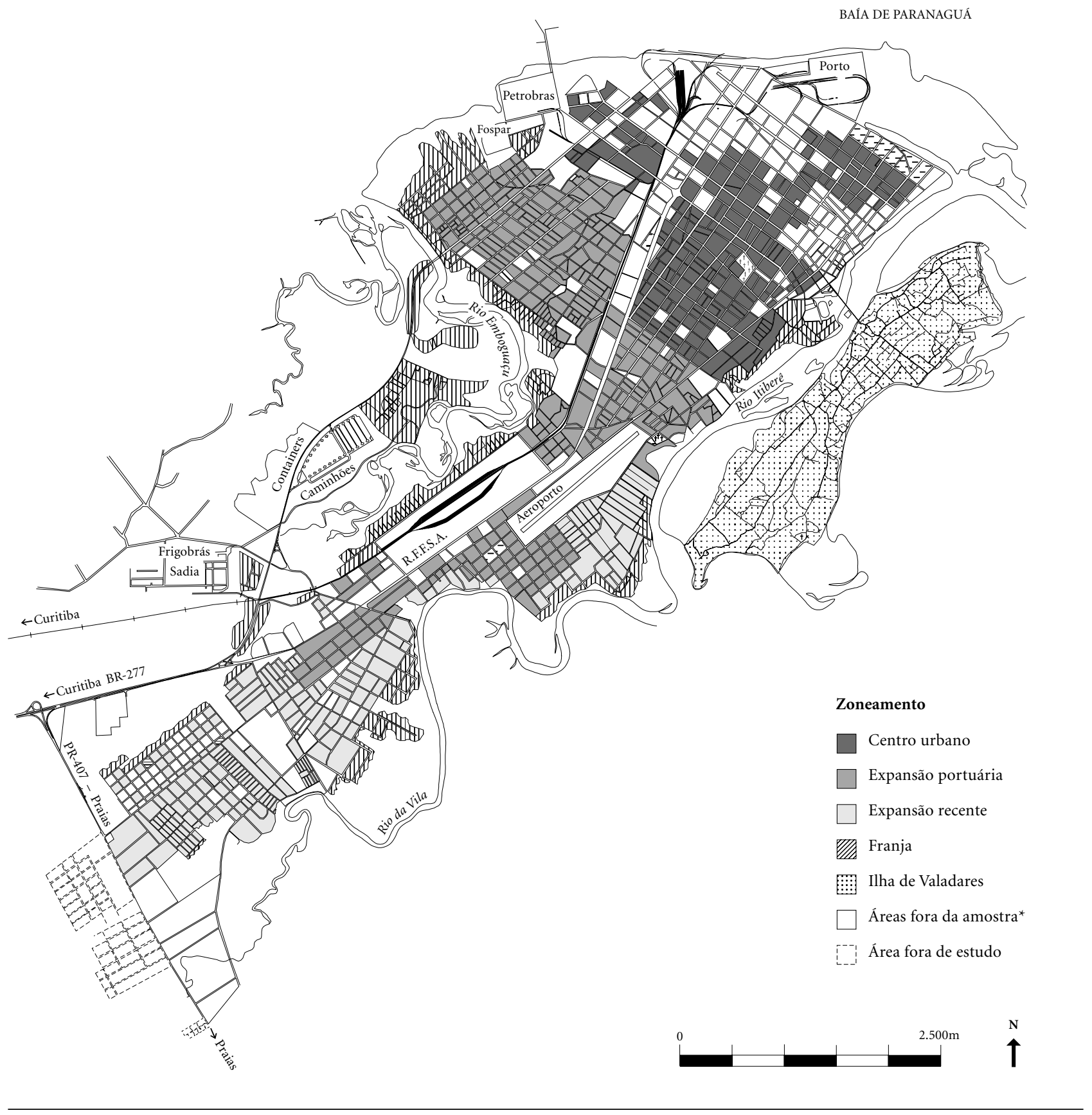

Fonte: Gerhardt, T.E., 2000. Base Cartográfica - Prefeitura Municipal de Paranaguá, 1996.

* Setores administrativos, comerciais, públicos, atividades portuárias, áreas não ocupadas 
Figura 2

Distribuição dos estratos socioeconômicos de acordo com as diferentes zonas da cidade de Paranaguá - 1996

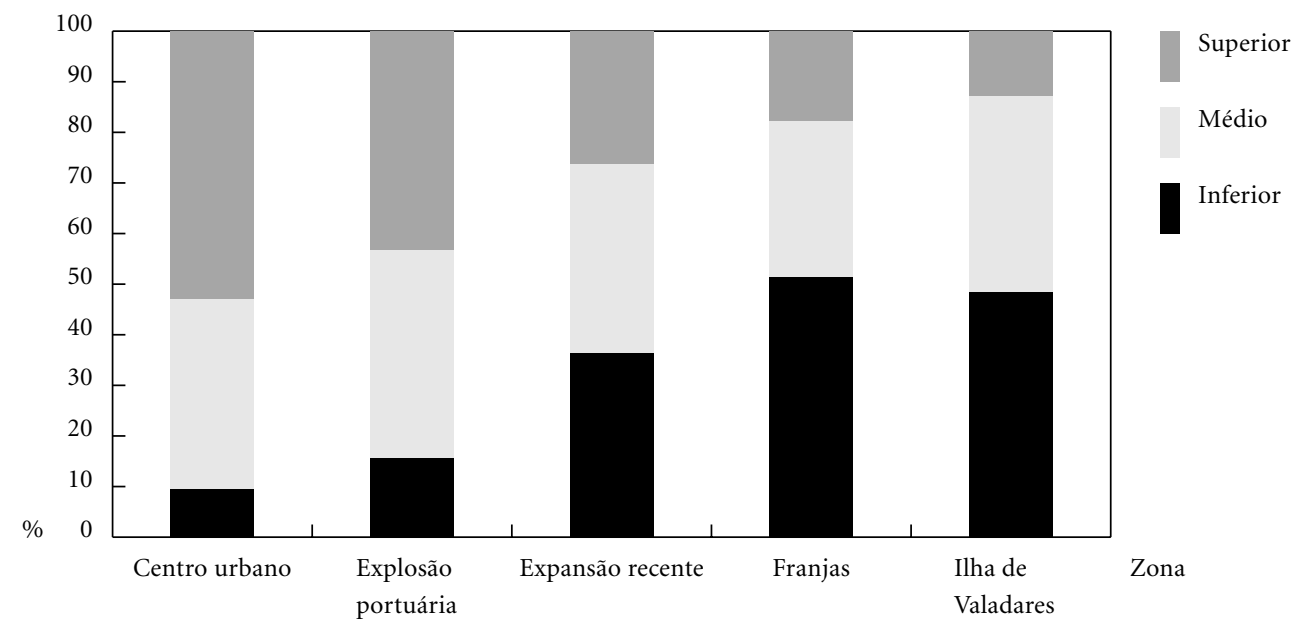

Fonte: Gerhardt, T.E., 2000

através de programas sociais, ao mesmo tempo em que se aproveitam para transmitir sua visão de mundo. A ajuda não é, portanto, gratuita, ela tem um preço, seja em termos monetários, seja em termos de fidelidade.

\section{Aspectos do quadro material e social da moradia}

Certos aspectos da vida cotidiana, como a moradia e a alimentação, compõem o quadro geral no interior do qual os indivíduos desenvolvem estratégias de enfrentamento das dificuldades econômicas. No que diz respeito mais especificamente às diferenças entre essas duas zonas, as diferenças são mais visíveis no plano da organização espacial do quadro de vida e das estruturas sociais (familiares e comunitárias), conseqüências de estratégias de moradia materiais e sociais diferentes (Gerhardt et al., 2002).

A Ilha de Valadares apresenta uma situação bem diferente, pois se distingue claramente das outras zonas da cidade, como já mencionado. Do ponto de vista social, Valadares distinguese particularmente por possuir uma articulação mais intensa entre os laços de parentesco e as relações de vizinhança: as famílias extensas são mais numerosas, e mesmo no caso das famílias nucleares, o parentesco reside na proxi- midade e contribui ao desenvolvimento de relações mais intensas.

Já na zona das Franjas, o parentesco está distante geograficamente para a maioria das famílias, e notamos um desenvolvimento importante de outros tipos de relações: os problemas cotidianos podem gerar o desenvolvimento de relações desiguais e dependentes com o poder local (vereadores), com patrões, com igrejas, etc., relações fundamentalmente "verticais", sendo que em Valadares, trata-se mais de relações "horizontais", mais iguais.

Os resultados obtidos mostram os múltiplos recursos utilizados pelos mais desfavorecidos na tentativa de enfrentar a precariedade de suas condições de vida. $\mathrm{O}$ apelo a diversos tipos de solidariedade familiar, de vizinhança e da comunidade é mais freqüente no caso de Valadares. A inscrição em redes "paternalistas" é igualmente presente, mas aparece de forma mais visível nas Franjas. Permite, sobretudo, usufruir ao máximo a ajuda fornecida pelos serviços sociais (da prefeitura, das igrejas, das relações interpessoais). A ajuda disponível e a ajuda solicitada variam de acordo com as necessidades sentidas como tais. Em certos casos, a rede familiar pode estar presente. Em outros, as famílias desfavorecidas devem recorrer às instituições religiosas ou públicas. Essa capaci- 
dade em mobilizar diferentes formas de ajuda pode ter implicações sobre o estado de saúde dos indivíduos.

As famílias que possuem uma maior ou menor capacidade em diversificar suas fontes e a procurá-las, caso seja necessário, longe de sua zona de residência, escapam das limitações de seu ambiente próximo. Assim, a entre-ajuda associada à satisfação das necessidades essenciais da vida cotidiana não é influenciada pela forma das redes (ampla ou restrita, próxima ou distante). É fortemente modulada pela trajetória individual da mulher principal da família, pois é graças ao papel que ela desempenha na mobilização das redes familiares e comunitárias que a família passa a ter um papel protetor, ou ao menos moderador, dos problemas econômicos aos quais são confrontados. A situação econômica é naturalmente um elemento importante de restrições as quais as famílias devem enfrentar para poder preservar sua saúde ou, ao menos, para evitar a doença. De fato, eventos marcantes da vida cotidiana - perda do trabalho, doença, morte - podem provocar um desequilíbrio no funcionamento familiar já fragilizado pela situação econômica, sendo o papel da mulher essencial na procura de respostas a esses problemas.

\section{Circulação de alimentos e mobilização de redes sociais}

Os resultados obtidos pela enquete epidemiológica mostram uma diferenciação não muito acentuada de desnutrição crônica em crianças menores de 10 anos, levando a pensar que os recortes espaciais e sociais, com os quais descrevemos a realidade atual da cidade de Paranaguá, não são suficientes para explicar as concretas situações de vida e fazem pensar na existência de estratégias de enfrentamento desenvolvidas pelos atores diante da carência nutricional (Nazareno, 1999). Os processos de diferenciação de crescimento espacial e demográfico, de nível socioeconômico, de acesso ao trabalho formal, parecem não ser suficientes para criar fortes disparidades em termos de alimentação e saúde. Isso não significa que a melhoria das condições materiais de vida não tenha efeito sobre a saúde, mas quer dizer que existem outros fatores que mascaram ou amenizam a influência positiva da evolução do quadro de vida. Esses fatores possuem raízes na dimensão cultural e social que abranda as tendências que levam à desigualdade.
Existem em Paranaguá múltiplos tipos de redes de trocas de bens e produtos. $\mathrm{Na}$ vida cotidiana das famílias pobres, no plano do núcleo familiar e da família (no sentido do parentesco), as redes constituem uma estratégia importante de sobrevivência e é nelas que os alimentos cotidianos são obtidos, criando esferas mais amplas de distribuição de alimentos e de sobrevivência. Em certas áreas da cidade, como o caso de Valadares, a forma de rede mais comum encontrada é a familiar. A enquete antropológica mostra que as famílias com laços de parentesco, mesmo tendo estatutos socioeconômicos diferentes, residem na maioria das vezes à proximidade um dos outros, tendo casos onde coabitam num mesmo lote. Essa proximidade espacial torna possível um fluxo mais intenso de trocas de produtos alimentares. Situação que não pode ser verificada nas Franjas, onde os laços de parentesco encontram-se distantes e que leva ao desenvolvimento de uma forma de rede mais comunitária com o surgimento de relações clientelistas, paternalistas e de dependência (Gerhardt et al., 2002).

Nesse sentido é preciso compreender que a situação econômica precária leva ao desenvolvimento de estratégias de ordem individual, mas também comunitária: as relações clientelistas, as procuras de prestígio, os deveres religiosos de caridade, tecem redes de distribuição entre famílias, vizinhos e outras instituições que amenizam as diferenças materiais que uma simples observação das condições externas de riqueza e pobreza tende a demonstrar e a esconder. É muito significativa em famílias pobres a participação em redes de trocas de alimentos, sendo que a situação nutricional de suas crianças é claramente melhor do que as que não participam. As condições reais de existência de uma família podem, portanto, depender muito mais das redes de solidariedade às quais pertencem e da capacidade das mulheres (pilar central do núcleo familiar nestes casos) de se integrarem nessas redes, do que do quadro de vida material dentro do qual vivem. É preciso também notificar que quanto mais próximos geograficamente forem os laços de parentesco, mais chances temos de encontrar o desenvolvimento de estratégia que envolva a rede familiar. Laços de parentesco distantes geograficamente proporcionam o desenvolvimento de estratégias diferentes como a mobilização de redes comunitárias que envolvam relações clientelistas, de dependência entre a família e as instituições procuradas (prefeitura, vereadores, igrejas). 
As diferenças não muito acentuadas que se observam no plano nutricional de crianças pertencentes a diferentes categorias socioeconômicas e residentes em zonas distintas da cidade apontam - ao menos em parte - para dois aspectos. De um lado, para a eficiência dos mecanismos familiares e comunitários que evita aos mais pobres o impacto direto das suas condições de vida precárias. De outro lado, para os limites das estratégias que as categorias mais abastadas aplicam às suas crianças, ao menos no campo alimentar. Encontrar crianças com desnutrição crônica nas categorias avaliadas pela enquete epidemiológica (quase $7 \%$ no estrato superior) leva a pensar novamente que as condições de vida materiais são insuficientes para evitar o problema, que pode estar ligado muito mais a um ambiente de carência afetiva, a problemas de ordem psicológica e a conflitos familiares que podem afetar a situação nutricional. Os hábitos alimentares de base variam pouco entre famílias do estrato superior e inferior, sendo que a situação nutricional das crianças mostra que a relação entre o indivíduo e seu ambiente físico é muito mais complexa e menos direta do que se pensa. Ela passa pela mediação dos fatos e dos comportamentos sociais e culturais.

A mulher e as crianças constituem o núcleo central no que diz respeito à preparação e ao consumo de alimentos. Mas em certos casos, a família no seu conjunto, seja uma família extensa ou uma família nuclear (dispondo ou não de um sistema de parentesco próximo geograficamente), representa o nível mais significativo e mais estável de entre-ajuda no abastecimento alimentar. Fora da família, em outras situações, é no seio do espaço social mais amplo que circulam e distribuem-se os gêneros alimentícios. Trata-se da entre-ajuda entre vizinhas, entre amigos, de laços de dependência pessoal (relações paternalistas - estratégia ativa de legitimação da dominação entre a população e os vereadores, entre a população e as igrejas católicas e pentecostais, entre a população e os sindicatos).

A alimentação consumida pela família provém assim de várias fontes: cozinha familiar, dons (vizinhos e amigos), compras a fiado, merenda escolar, cesta básica (prefeitura, igrejas, vereadores, sindicatos), Pastoral da criança. As fontes, além da cozinha familiar, representam uma parte importante da alimentação consumida, e as estratégias são bastante diversas. Aqui também o papel da mulher é preponde- rante na capacidade em mobilizar tais recursos. $\mathrm{Na}$ amostra estudada, o aporte exterior constitui para certas famílias o único aporte que elas possuem para se alimentar.

Um exemplo concreto contribui a evidenciar a que ponto os problemas alimentares podem passar por uma estratégia coletiva, no seio da qual as solidariedades femininas e a capacidade individual exercem um papel fundamental. No cotidiano, as trocas são muito mais densas e variadas do que as esquematicamente apresentadas neste exemplo, mas ele ilustra a mobilização de redes familiares e comunitárias, na zona das Franjas (Figura 3). Todas as cinco famílias envolvidas nesta rede estão confrontadas com importantes problemas econômicos. Dois dos chefes de família possuem um trabalho irregular e ausentam-se ao longo do dia, deixando suas famílias sozinhas. Um fator agravante acrescenta-se a esta situação: os dois são alcoólatras e, em diversas ocasiões, após terem recebido o pagamento do trabalho semanal, gastam a metade do valor recebido em bebidas alcoólicas consumidas com os colegas na saída do trabalho. O terceiro chefe de família possui um emprego estável, embora receba apenas dois salários mínimos. As duas outras famílias (compostas por uma viúva e uma mãe solteira) sobrevivem com a pensão de um salário mínimo. Em termos de proximidade geográfica, a mãe solteira e o chefe que possui um emprego e um dos chefes alcoólatras são vizinhos. Os demais não moram na mesma zona, apesar de terem parentesco com os outros.

Essa rede familiar e de vizinhança funciona como uma comunidade solidária, alimentada a cada vez graças às iniciativas e as relações pessoais de cada um dos participantes; elas permitem amplamente o enfrentamento das dificuldades econômicas. Uma das mulheres ocupa a posição central no funcionamento da rede como "fornecedora" de alimentos graças ao acesso privilegiado que ela soube obter junto a uma gama de fontes exteriores: a cesta básica (obtida com a prefeitura, ou com o vereador, ou ainda com a igreja), o trabalho informal (venda de panos de prato, de produtos cosméticos), o acesso à compra fiado com o comerciante local. Cada um dos participantes contribui, no entanto, segundo as suas possibilidades, para manter as trocas. Em relação a isso, pertencer a outros círculos de sociabilidade pode ser igualmente determinante: mesmo pouco freqüente ou precário, o apoio do parentesco ou de amigos constitui um aporte precioso que susten- 
Figura 3

Trocas alimentares entre famílias aparentadas e não-aparentadas

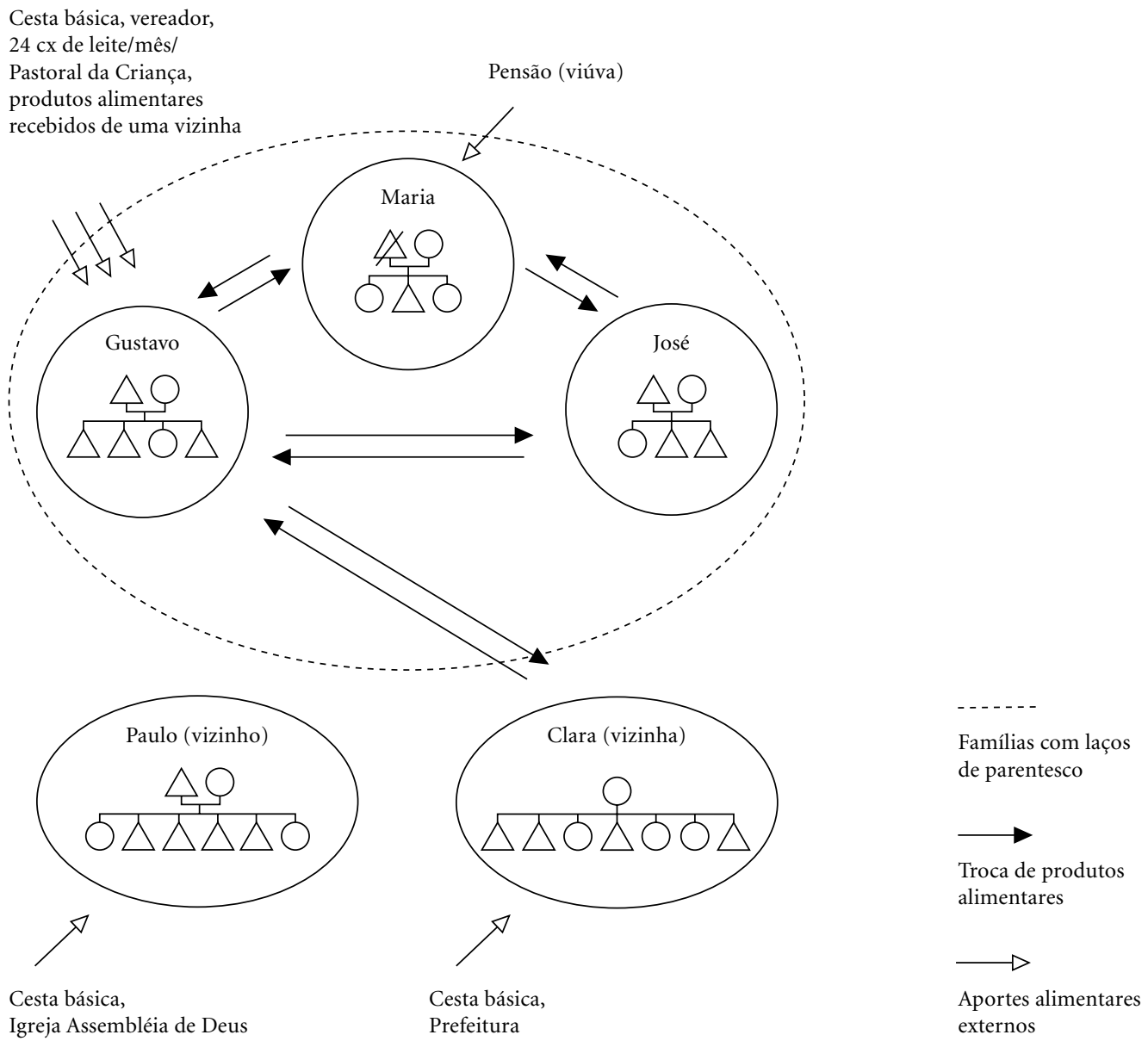

Fonte: Gerhardt, T.E., 2000

ta o conjunto do sistema. Em situações extremas, verdadeiros sacrifícios são realizados: a venda de um móvel da casa, de um rádio ou de pequenos bens de consumo adquiridos dificilmente, mas cuja função é, segundo eles, menos importante que a alimentação.

Nessas redes, cada um contribui com o que possui em casa, com o que podem compartilhar, mas existe uma rotatividade informal dos aportes, de maneira que eles não contribuem todos com o mesmo produto e a mesma quantidade ao mesmo tempo, o que não os impede de serem beneficiados pelas trocas de produtos entre os diferentes parceiros. Esse desequilíbrio poderia ter efeitos negativos, como a durabili- dade da rede, mas a "não-cobrança" é bem-vinda nos dias em que a situação está realmente difícil. O caráter informal da rede não compromete a sua durabilidade pelo fato de, cedo ou tarde, haver a possibilidade de contar com a reciprocidade. De qualquer forma, as trocas estão sempre disponíveis, de maneira que as mulheres que fazem parte da rede extensa de relações têm sempre uma forma de garantir, a ela e as suas crianças, ao menos uma refeição por dia.

O que se observa nesse tipo de rede é a existência de um modelo concêntrico, com um núcleo central, em que a família está no centro das trocas e as relações estão baseadas na igual- 
dade e na reciprocidade. Por outro lado, há um ambiente social no interior do qual vive a família, que permite o estabelecimento de relações nas quais a ajuda obtida contribui para amenizar a situação de crise, mas que ao mesmo tempo conduz ao desenvolvimento de relações desiguais e de dependência.

A ajuda alimentar oriunda de fontes externas provém em grande parte, no caso deste exemplo, da distribuição de cestas básicas. Para beneficiar-se dessa ajuda é preciso estar inscrito no programa de distribuição da prefeitura e as condições de admissão dependem muito da situação econômica da família. Essa situação varia muito no tempo, pois os chefes de família possuem um trabalho informal e irregular, tornando-se difícil mesmo para a prefeitura manter as listas atualizadas, beneficiando as famílias que realmente necessitam. É nesse sentido que a capacidade individual de cada mulher torna-se importante: ela consegue intervir junto aos responsáveis da distribuição de cestas básicas. As igrejas, sobretudo as igrejas pentecostais e a igreja católica (através do seu programa comunitário da Pastoral da Criança), possuem um papel igualmente importante na distribuição das cestas básicas, e a lógica parece ser a mesma da lógica do poder local: estabelecer relações paternalistas (papel protetor, fornecedor e de redistribuição) que mascaram as desigualdades e a ideologia subjacentes.

Uma cesta básica é importante para uma família, embora ela seja suficiente somente para 15 dias. Além disso, freqüentemente, a família beneficiária divide a cesta básica com os outros membros de sua rede, mesmo que isso signifique que os alimentos assim divididos não serão suficientes por muito tempo e que outras estratégias deverão ser colocadas em prática para assegurar o aporte alimentar nas semanas seguintes. O que parece ser importante para eles é a satisfação das necessidades imediatas. Todavia, isso depende mais uma vez da capacidade de cada mulher de tomar a iniciativa para resolver o problema: acostumadas a receber esse importante aporte alimentar, certas mulheres não se preocupam em procurar outras alternativas mais duráveis. Mesmo no interior dessas redes, a situação de cada família não é a mesma e a capacidade da mulher que desempenha o papel central é decisiva. Todos esses aspectos colaboram para a definição da noção de situações de vida, em que os indivíduos possuem capacidades diferentes para construir suas situações de vida e para tomar em mãos suas vi- das, em função de seu nível socioeconômico, das características de seu ambiente físico e social e de suas capacidades e histórias de vida individuais.

\section{Considerações finais}

Vimos perfeitamente neste texto como as estratégias individuais e coletivas são complementares nas situações de penúria. Seria difícil para as famílias se manterem se cada uma dentre elas não investisse em termos de recursos pessoais. Para isso, cada uma tenta valorizar seus talentos e aproveitá-los: a ajuda de um parente ou de um amigo, o acesso aos responsáveis do poder local, os bicos realizados, etc. É interessante observar que esses tipos de estratégias foram encontrados em Maradi (Niger) na África, onde as mulheres ocupam posição central na sociedade haoussa no que se refere à subsistência familiar (Raynaut, 1992a, b), o que demonstra o caráter mais global desse tipo de estratégia.

De acordo com a capacidade da mulher, os recursos sociais mobilizados irão amenizar as desigualdades existentes em todos os planos da vida cotidiana. As práticas referentes à alimentação e moradia mostram as relações complementares e cumulativas, e não substitutivas, entre a entre-ajuda familiar e a criação de redes na esfera comunitária. A mobilização de recursos e a formação de redes são o resultado das necessidades sentidas pelos indivíduos em termos de problemas cotidianos. A situação vivenciada pelas famílias desfavorecidas, de acordo com a forma como ela é percebida pelos indivíduos, pode ou não gerar estratégias de enfrentamento aos problemas. A vulnerabilidade das famílias é assim associada à percepção que elas possuem de suas próprias situações de pobreza e do perfil das desigualdades sociais. Mas a entre-ajuda é somente um dos elementos que compõem as relações humanas, feitas em parte de "esperas interessadas", mas também de gratuidade e de espontaneidade. É a dinâmica das relações humanas que está na base da estrutura das redes e das formas de entre-ajuda. Assim, as redes de entre-ajuda não podem ser isoladas do contexto que as fazem emergir e da dinâmica das relações interpessoais, ou seja, da empatia, das relações afetivas, das relações de companheirismo, dos gestos gratuitos dificilmente quantificáveis.

O cotidiano dessas mulheres - seus sofrimentos e desesperanças, suas ambigüidades en- 
tre conformismo e resistência, entre o olhar do outro e a aceitação, entre a resignação e a esperança - suscitou questões e evidenciou a importância das mulheres na gestão cotidiana dos problemas e no estabelecimento de prioridades. As famílias estudadas mostraram que apesar de sua marginalização social, elas conseguem criar práticas originais, reinterpretar idéias e sugestões, reinventar o concreto e fazer de suas vidas uma travessia balizada de partilhas e de mudanças. Encontrar soluções, reinventar a partir do nada, recriar uma vida coletiva, tudo isso possui uma expressão simbólica expressiva, portadora de ensinamentos, que um olhar distante é incapaz de compreender.

Cada um intervém como um ator que, mesmo sendo tributário de um certo quadro de vida material, social e cultural, o reinterpreta em função de estratégias que lhe são próprias e com a ajuda das quais constrói uma situação de vida que lhe seja específica. As estratégias e situações construídas são, no entanto, provisórias e precárias: submetidas ao choque de um evento individual ou familiar (modificação da situação profissional ou residencial, conflitos familiares, doenças, etc.), mas também às dinâmicas mais progressivas de melhoria ou de degradação da situação econômica. Por outro lado, é preciso cuidar para interpretar as práticas alimentares e de moradia de forma unicamente individualista. Qual seja a margem de manobra individual, os atores sociais inserem-se em estruturas de entre-ajuda e de partilha cujas normas e valores da sociedade possuem uma influência sobre as escolhas e sobre seu comportamento.
Das reflexões formuladas e expostas neste texto, podemos destacar dois pontos importantes referentes à forma de abordar as questões das desigualdades de saúde e de suas relações com as desigualdades sociais no campo da saúde coletiva.

Em primeiro lugar vimos que para termos a medida justa da realidade social e de saúde não podemos nos contentar com uma análise relizada a partir de indicadores macro-descritivos. É preciso realizar análises aprofundadas da realidade através de uma observação fina das representações e das práticas das populações envolvidas. Neste caso, a complementaridade entre a antropologia e a epidemiologia se faz presente, uma vez que esta última dispõe somente de instrumentos que permitem uma categorização distante e estática do real (Raynaut et al., 2002).

Em segundo lugar, podemos pensar que uma política pública de saúde não pode ser centrada exclusivamente sobre a oferta de meios e de serviços concebidos a partir do saber de um especialista. Ela deve refletir as capacidades de resposta e de inovação que testemunham - em um nível individual e também coletivo - as populações que são o objeto de promoção de saúde. O apoio a iniciativas e inovações locais é hoje uma das linhas de força de muitos projetos de desenvolvimento e pode contribuir de forma significativa para o desenvolvimento de propostas de ações mais efetivas em saúde coletiva. 


\section{Referências bibliográficas}

AG Bendech M Chauliac M \& Malvy D 1996. Variabilité des pratiques alimentaires à domicile des familles vivant à Bamako (Mali) selon le niveau socio-économique. Cahiers Santé 6(5):285-297.

Caneparo SC et al. 1996. Espaço urbano, situações de vida e saúde na cidade de Paranaguá: relato preliminar de uma prática interdisciplinar. Cadernos de Desenvolvimento e Meio Ambiente 3:35-48.

Déchaux JH 1996. Famille et solidarité. Revue Sciences Humaines 13:32-35.

Degenne A \& Lebeaux MO 1991. L'entraide entre les ménages: un facteur d'inégalité sociale? Sociétés Contemporaines 8:21-42.

Degenne A \& Forse M 1994. Les réseaux sociaux. Une analyse structurale en sociologie. Armand Colin, Paris.

Fougeyrollas-Schwebel D 1994. Entraide familiale: de l'universel au particulier. Sociétés Contemporaines 17: 51-73.

Gerhardt TE et al. 1996. Heterogeneidades e homogeneidades do quadro de vida urbano de Paranaguá. Relatório de pesquisa - Programa Interdisciplinar de Pesquisa Espaço Urbano, Situações de Vida e Saúde: o caso de Paranaguá. Doutorado em meio ambiente e desenvolvimento, UFPR.

Gerhardt TE et al. 1997. Desigualdades sociais e situações de vida em Paranaguá. Relatório de pesquisa, Programa Interdisciplinar de Pesquisa Espaço Urbano, Situações de Vida e Saúde: o caso de Paranaguá. Doutorado em meio ambiente e desenvolvimento, UFPR

Gerhardt TE 1998. Tamanho das famílias, estrutura familiar e mobilização de "recursos sociais" em Paranaguá. Relatório de pesquisa, Programa Interdisciplinar de Pesquisa Espaço Urbano, Situações de Vida e Saúde: o caso de Paranaguá. Doutorado em meio ambiente e desenvolvimento, UFPR.

Gerhardt TE 2000. Anthropologie et santé publique: approche interdisciplinaire. Pauvreté, situations de vie et santé à Paranaguá, Paraná, Brésil. Tese de doutorado, Departamento de Antropologia Social e Cultural, Université de Bordeaux 2, Bordeaux.

Gerhardt TE \& Nazareno ER 2002. Diálogo entre a epidemiologia e a antropologia nas questões de saúde, pp. 103-125. In C Raynaut et al. (orgs.). Desenvolvimento e meio ambiente: em busca da interdiciplinaridade. Pesquisas urbanas e rurais. Editora UFPR/ Unesco, Curitiba.
Hubert A \& Sancho-Garnier H 1992. Anthropologie et épidémiologie nutritionnelle. Cahiers des Sciences Humaines 28(1):57-65.

Massé R 1995. Culture et santé publique. Les contributions de l'anthropologie à la prévention et à la promotion de la santé. Gaëtan Morin Éditeur, Montreal.

Nazareno ER 1999. Condições de vida e saúde infantil: heterogeneidades urbanas e desigualdades sociais em Paranaguá, Brasil. Tese de doutorado, Doutorado em meio ambiente e desenvolvimento, Universidade Federal do Paraná, Curitiba.

Raynaut C 1992a. Approches sociales de l'alimentation infantile en milieu urbain africain. Guide méthodologique. L'Enfant en Milieu Tropical 201.

Raynaut C 1992b. Se nourrir en ville: stratégies économiques et pratiques sociales (Le cas de maradi, Niger), pp. 141-198. In Ch. Blanc-Pamard (org.). La santé en société. Regards et remèdes. ORSTOM, Paris.

Raynaut C 1996. Processo de construção de um programa interdisciplinar de pesquisa no quadro do doutorado em meio ambiente e desenvolvimento (MAD/ UFPR). Cadernos de Desenvolvimento e Meio Ambiente 3:23-33.

Raynaut C, Gerhardt TE \& Nazareno ER 2002. Pauvreté, inégalités économiques et disparités de santé: conditions de vie et stratégies d'acteurs. Revue Face à Face. Regards sur la Santé 4:3-20.

Woortmann K 1978. Hábitos e ideologias alimentares em grupos sociais de baixa renda. Relatório técnico - Série Antropologia no 20. Universidade de Brasília, Brasília.

Woortmann K 1985. A comida, a família e a construção do feminino. Relatório técnico - Série Antropologia no 50, Brasília: Universidade de Brasília, Brasília.

Zaluar A 1982. As mulheres e a direção do consumo doméstico. Estudo de papéis familiares nas classes populares urbanas, pp. 161-184. In Colcha de retalhos: estudos sobre a família no Brasil. Ed. Brasiliense, São Paulo.

Artigo apresentado em 21/1/2003

Aprovado em 30/3/2003

Versão final apresentada em 5/4/2003 